\title{
The Disaster Approach: Countering Learner Apprehension in Role-Play
}

Management Teaching Review 2018, Vol. 3(2) 172-180

(C) The Author(s) 2017

Reprints and permissions: sagepub.com/journalsPermissions.nav DOI: 10.1 I 77/2379298। I 7728706 journals.sagepub.com/home/mtr

@AGE

\section{Paul Donovan' and John Townsend²}

\begin{abstract}
Training programs enhance the skills of participants. Role-play, one method used for such skill development, is learning through performing a set of behaviors, in accordance with predetermined expectations of a job role in an organizational context. Some learners find role-play daunting, even traumatic. To counter this experience, this article shows an innovative role-play format where, in advance of the program, tutors design and create a "disaster" video-an encounter where almost everything goes awry. In class, the video is shown and the group is divided into two teams: and one team designs and demonstrates a "corrected" version of the encounter. The second team composes a set of best practices on the ideal way to conduct such an encounter. The role-play event is performed in plenary by the "Demonstration" team, and the "Best Practices" team applies their guidelines to the other team's performance. Instructions on how to use the exercise are given.
\end{abstract}

\section{Keywords}

soft skills, training, role-play, acting, skills, behavior training, apprehension

\section{Role-Play in Learning: Issues and Solutions}

Role-play is a well-known tool for trainers and facilitators to help participants learn necessary skills in training programs, but many are apprehensive about participating in them (Alden, 1999; Castleberry, 1989; McDonald, 2006; Richardson \& Kleiner, 1992; Taplin, 2007). A mild level of apprehension may be useful for learner performance, but if anxiety levels rise then the apprehension may interfere with the learning

\footnotetext{
'Maynooth University, Kildare, Ireland

${ }^{2}$ Consultant, Mas la Papesse Cavillargues, France

Corresponding Author:

Paul Donovan, Maynooth University, Rowan House, Rowan Road, Kildare, Ireland.

Email: Paul.donovan@nuim.ie
} 
of the participant (Butler, 1986). In some instances, it may create trauma for learners (Castleberry, 1989; Tanner \& Chonko, 1992). Additionally, if there is apprehension, learners may use energy to reduce anxiety and protect their self-image rather than to practice new skills.

To counter these issues, it is recommended that tutors take steps to deal with apprehension in students regarding role-play (Jones \& Javie, 1996). In this article, an alternative role-play model is described that combines the elements of learner control and autonomy as a countermeasure to apprehension. Karim and Behrend (2014) suggested that learner control fosters perceptions of autonomy that result in positive training reactions. Learner control is defined as the degree to which trainees have discretion in making decisions about their training (Karim \& Behrend, 2014). Additionally, Druckman and Ebner (2007) suggest that learners, who are involved in the design of experiential activities, learn more than the role-players who participate in the simulation. In their study, they showed that designers of role-plays claim to get more out of their experience than do role-players, and in addition, designers learn more about the concepts being taught than their "onstage" role-play counterparts (Druckman \& Ebner, 2007).

This new role-play method works because of pedagogical and human reasons. At a pedagogical level, the method resonates more with constructivist learning theory than with prescriptive approaches to teaching. Constructivist theory of learning suggests that the existing knowledge that students draw on from their context is not a "passive and inactive storage of information" but rather something they use in class to construct new knowledge (Mishra, 2015). This role-play method draws heavily from these ideas. In addition, the method removes many of the psychological and emotional barriers that learners experience whenever they are called upon to perform a role-play. At a human level, the new approach removes the unknown and threatening elements of traditional role-play. When the learner is placed in control, he or she can dedicate his or her energies to identifying those behaviors that will transfer most effectively back into real life. This method allows learners to locate their learning contextually even when they are in the formal classroom situation. Traditional role-play may create contextual problems because learners are often offered "correct" prescriptions on how to behave, which they in turn find difficult to transfer to their own unique world. This way offers a way for learners to create authentic approaches based on their own intimate knowledge of their job context that they know will succeed in their world.

This revised approach also affects the role of the educator/facilitator. Rather than fully prescribe to passive students the "right" way to do things, this approach places the tutor in the role of guide and mentor. Instead of handing down prescriptions regarding job behavior to learners, the tutor acts in a Socratic role by setting up a problembased case study and by gently challenging the students to construct their own context-based solutions.

In our experience, learners prefer this method to the traditional role-play approach. Both the Demonstration and Best Practices teams tend to have increased energy when problem-finding as they try to right the wrongs of the video example. This approach also generates an element of useful competition between teams: The Demonstration team wishes to surpass the expectations of the forthcoming Best Practices evaluation; 
the Best Practices team seeks to provide a comprehensive set of guidelines (including perhaps, some the other team may have missed). A wise facilitator will ensure that the Best Practices are not perceived as being complete and will gently press that both teams try to improve this list.

The choice of the "disaster" scenario may seem, at first, counterintuitive. However, Malouff, Thorsteinsson, Schutte, and Rooke (2009) have shown how the viewing of a model experiencing negative outcomes for performing a behavior led to a significantly lower level of the behavior by the observers. Drawing on these research findings, a revised approach to role-play is described in detail in this article. This approach is largely based on negative vicarious learning described in observational learning theory (Bandura, 1986). In negative vicarious learning, the learners note the behavior and its negative consequences, have a negative emotional reaction to the consequences, and want to avoid the consequences themselves. Observers in these situations display lower rates of the unwanted behaviors post learning (Malouff et al., 2009).

\section{Learning Objectives}

At the end of the Role Play Disaster exercise, participants will have

- Identified negative behaviors that require alteration

- Identified positive, alternative, and context-based behaviors that need to be learned

- Practiced these behaviors in a supportive environment without apprehension

- Examined the relevance of the behaviors toward the context to which they will be transferred

- Experienced autonomy and control in the learning situation

\section{Overview of the Role-Play}

This new technique, described in Appendix A, overcomes apprehension issues with role-plays and is based on the principle of putting the learner in control, thereby mitigating the element of apprehension. In role-play exercises, learners are often invited to play loosely defined roles as they attempt as individuals to enact "correct" behaviors to repeat these in the workplace. In this revised approach, the tutor creates a "disaster" video based on the intended learning objectives. For example, it could involve a manager conducting a disciplinary interview with a staff member with the manager making a series of errors - each error being a negative mirror image of the intended learning objective. This video provides scaffolding for the participants from which they may construct their learning. In the classroom setting, the plenary group is invited to watch the resultant video and they are encouraged to note every error they can identify. Following the viewing of the video, learners are divided into two teams - the Demonstration Team and the Best Practices Team. The Demonstration Team is tasked with planning and performing the re-creation of the disaster scenario in a way that addresses or avoids the mistakes made in the video they have just seen. Following the 
planning phase, volunteers from the Demonstration Team enact this new and revised scenario in front of the plenary group. The task of the Best Practices Team is to create a poster checklist that provides specific guidelines to avoid the mistakes made in the video they have just seen.

In the following plenary session, the Demonstration Team enact their revised scenario attempting to reverse all the problems they have seen in the video. During the reenactment, everyone from the Best Practices Team uses their checklist to evaluate how well they think the Demonstration Team has done their task of providing a "perfect" scenario. At the end of the reenactment, the Best Practices Team presents their observations and feedback to the Demonstration Team who may respond. The facilitator helps debrief and reconcile views of participants and may, of course, add recommendations as appropriate.

In advance of the session a "disaster" should be created, usually by the tutor-a sample script is shown in Appendix B and a sample video may be found at https:// vimeo.com/159029253. Video production, once the preserve of professionals, can now be achieved by tutors with a smartphone using any one of the many free apps available today. With experienced learners, this task could be delegated to them, and they would thus benefit from being placed in the designer role, which also leads to improved learning (Druckman \& Ebner, 2007). However, because the task requires a command of the learning objectives to be achieved, it is preferable to have the tutor create the "disaster" video.

\section{Designing the "Disaster" Video}

The success of this approach to role-play depends largely on the video-it is the essence of the whole session. We call it the "disaster" video because its purpose is to illustrate what can go wrong when the appropriate skills are not used. The design of any such learning instrument begins first with outlining the intended learning objectives or outcomes to be able to create the negative examples for the video. Learning objectives are usually written as behavioral statements, specifying the behaviors to be acquired.

The design and creation of the video is usually done by the tutor or, in exceptional circumstances, it may be delegated to some experienced learners in advance of the program. Typically, the tutor has a greater command of the learning requirements and objectives to be achieved. Experienced learners who engage in design of role-plays will learn more from doing so (Malouff et al., 2009). Post-experience learners may have more resources to draw upon here, and pre-experience learners may need some support in reaching an acceptable solution. Both types of learners will need to create or select some negative "vignettes" that are evocative of the behaviors to be addressed and corrected and that reflect the learning objectives. Although this article is aimed at management education, this exercise may also be used in other disciplines.

In a corporate situation, it is probably best to find a disaster situation that does not identify real people but which features unacceptable (though reasonably credible) behaviors. Having decided on a vignette, the next step is to create a storyboard. A 
storyboard is a step-by-step outline, describing the sequence of events in the vignette. Next, it is vital to write a credible and simple script containing a negative example of each learning point. The making of the video does, of course, require a set, some actors, and a smartphone. Phone apps that enable video making are ubiquitous. The production values are much less important than the clarity of the scenario. For example, an interaction between a manager and employee could take place in a nonidentifiable corridor or sparsely furnished office environment; see an example at https:// vimeo.com/159031894. The players do not have to be trained actors - after all, we do not expect as much in the normal role-play situation. Try and keep the disaster videos to 3 minutes duration and include 5 to 10 examples of negative behavior covering the appropriate learning objectives (see attached screenplay in Appendix B). Appendix C contains examples of modules where the approach may be used. The level of detail provided in the video will depend largely on the experience levels of the participants. Post-experience audiences may prefer, and learn more from, less detailed videos as this will afford them the opportunity and freedom to construct solutions from their context.

\section{Timetable}

The role-play disaster can usually be executed in a class of 80 to 90 minutes duration as follows. Some tutors may find that, depending on their final design, a longer class is more satisfying.

- Introduce the exercise- -5 minutes

- Show the disaster video- 5 minutes

- Issue the instructions and form the teams- -5 minutes

- Demonstration Team activity and Best Practices Team activity-30 minutes

- Execution of "correct" role-play-10 minutes maximum

- Each team reflects on the exercise-5 minutes

- Best Practices Team makes their comments on the "correct" role-play-5 minutes

- Tutor leads debrief and plenary discussion-20 minutes

\section{When the Unexpected Crops Up}

This alternative role-play is a robust design that overcomes the apprehension issue inherent in role-plays and which is additionally a lively and interesting exercise. Nonetheless here are a few issues that might emerge:

Learning styles: We know there are different learning styles (Honey, 1986). Accordingly, it may be that activists and pragmatists feel let down when assigned to the reflective Best Practices Team. Similarly, theorists and reflectors may feel out of place in the "activist" Demonstration Team. The ideal solution is to allow learners to choose which team they join with the proviso that the same number joins 
the Demonstration Team as there are roles in the disaster video. In a large class setting, and with time constraints, it may be necessary to set up only one or two Demonstration Teams with the remainder of the students forming Best Practices Teams.

Possible disagreement with your "correct" answers: Due to the cultural and personal proclivities of your learners, people might disagree with your "correct" behavioral solution to the disaster video. Careful support and input during the teams' preparation phase and during the debriefing should be sufficient to head off such disagreements.

\section{Conclusion}

In certain circumstances, learners may experience apprehension, especially in the hands of inexperienced tutors and unstructured situations. Allowing increased levels of control and autonomy for learners may help them identify context-based behaviors that require amendment. This revised role-play approach encourages a supportive environment and reduces apprehension. In addition, it may also enhance the relevance of behaviors practiced in the classroom. The exercise allows the learners a designer role that has been shown to improve learning. Finally, the learners' freedom to create context-relevant role-play activities will enhance the possibility of postprogram transfer.

\section{Appendix A}

\section{Typical Session Structure}

This alternative role-play approach has a simple structure and a modest requirement for tutor intervention throughout the session. The role play activity is located at a point in time in the learning design where traditional teaching would have explained and/or demonstrated, in a didactic manner, the intended behaviors. The structure is outlined below.

Step 1: Introduce the topic and exercise and establish the link to the relevant learning objectives (5 minutes).

Step 2: Show "disaster" video. Ask learners to note all errors they perceive in the interaction shown (5 minutes).

Step 3: Ask the following, "If you were the manager/antagonist in this video example what would be the consequences of your behavior?" This question will allow learners to locate contextually the learning and to emotionally identify with the need to put things right.

Step 4: Divide the overall group into two teams-Demonstration Team and Best Practices Team - and issue instructions (5 minutes).

Step 5: The Demonstration Team prepares a reenactment of the disaster scenario showing how they would correct all the perceived flaws. This reenactment will 
entail rewriting the brief screenplay and coaching the volunteers who will play the focal roles (Planning and preparation time 30 minutes with tutor support).

Step 6: Contemporaneous with Step 5, the Best Practices Team creates a set of best practice guidelines that they will use to evaluate the forthcoming reenactment by the Demonstration Team. (We have found the most effective way to do this is a checklist with check boxes on a poster-Planning and preparation time 30 minutes with tutor support as required.)

Step 7: When the preparation time is up, invite the Demonstration Team to reenact their scenario. Ask everyone in the Best Practices Team to note, during the reenactment, where their guidelines have been met or not (10 minutes maximum).

Step 8: After the reenactment, give each team 5 minutes to reflect on the exercise. For the Demonstration Team, this may mean feedback to the "role-players." For the Best Practices Team, this will involve agreement on the extent to which the reenactment complied with the checklist.

Step 9: A representative of the Best Practices Team leads a feedback session to communicate how well, in their view, the Demonstration Team achieved their task (5 minutes).

Step 10: The tutor leads a debriefing session concentrating on any areas that were inadequately covered by either team, thus amending the Best Practices where necessary (20 minutes).

Step 11: The full group of learners can now practice the behaviors in triads with two learners being the "protagonists" and the third acting as observer, using the updated Best Practices list.

\section{Appendix B}

\section{Script for "Disaster" Video}

Paul is Tanya's manager. He has invited her to a meeting. Tanya enters Paul's office. He doesn't look up for a while. She sits.

Tanya: Hello, emm, Paul you wanted to see me?

Paul: Oh, eh, I can't remember why. Emm. Tanya, I want you to take over rostering as from first thing tomorrow. First thing you must do is go down to IT and get the passwords. Ok, good. (returns to his work)

T: But do you think I have enough experience? Can I really do that?

P: Sure, you do, sure you do you'll be fine.

T: Can you explain a little bit of the background? Why do we do this and why me?

P: Well, that will just slow us down. Just . . off you go . . . absolutely . . .

T: Uh, eh, how will I know that I'm doing it right? Can you explain a bit more about the outcomes, what you expect from me?

P: Yeah, but you're going to learn all about this as you go along, that's the whole point of this. You're going to learn as you go along. 
T: (Getting agitated). But wait! These are decisions about people, do I have authority for that? Do I have to consult with somebody on the top before I make them?

P: Details, details, details. I didn't get where I am today by asking questions and neither will you. Off you go now.

T: Can you tell me just how long you want me to be doing that? What's the end date of it?

P: More questions, Tanya. You are a funny one. I mean if I was in your position many years ago, I would be only too happy to take on this role.

T: Sorry, I don't think I have a complete understanding of that.

P: You're just a bit nervous that's all. But when you get started you'll be fine. Off you go.

T: Will there be any interim reviews and milestones just to check that I'm doing it right?

P: Oh, if you must, if you must . . o ok now we've a business to run here . . . off you go.

T: Paul will you be available to help me there if I need it?

P: (Already doing something else). What's that? Oh, sure, yeah, absolutely. Yes.

\section{Appendix C}

\section{Suitable Training Modules for Use of the Alternative Approach}

Conducting the performance discussion

Closing the sale

Handling the difficult customer

Delivering effective presentations

Reprimanding an employee

Selection interviewing

Chairing meetings

Facilitation skills

Reception skills

Negotiation skills

Coaching skills

Feedback on performance

\section{Declaration of Conflicting Interests}

The author(s) declared no potential conflicts of interest with respect to the research, authorship, and/or publication of this article.

\section{Funding}

The author(s) received no financial support for the research, authorship, and/or publication of this article.

\section{References}

Alden, D. (1999). Experience with scripted role play in environmental economics. Journal of Economic Education, 30, 127-132. 
Bandura, A. (1986). Social foundations of thought and action: A social cognitive theory. Englewood Cliffs, NJ: Prentice-Hall.

Butler, J. F. (1986). Personality characteristics of subjects high and low in apprehension about communication. Perceptual and Motor Skills, 62, 895-898.

Castleberry, S. B. (1989). Videotaped role playing in the personal selling classroom: A practical guide. Journal of Marketing Education, 11, 33-39.

Druckman, D., \& Ebner, N. (2007). Onstage or behind the scenes? Relative learning benefits of simulation role-play and design. Simulation \& Gaming, 39, 465-497. doi: $10.1177 / 1046878107311377$

Honey, P. (1986). Manual of learning styles (2nd ed.). Maidenhead, England: Peter Honey.

Jones, D. B., \& Javie, S. (1996). Anxiety level and causes in personal selling videotaped role plays. Marketing Education Review, 6(1), 19-26.

Karim, M., \& Behrend, T. (2014). Reexamining the nature of learner control: Dimensionality and effects on learning and training reactions. Journal of Business \& Psychology, 29, 8799. doi:10.1007/s10869-013-9309-6

Malouff, J., Thorsteinsson, E., Schutte, N., \& Rooke, S. E. (2009). Effects of vicarious punishment: A meta-analysis. Journal of General Psychology, 136, 271-285.

McDonald, R. E. (2006). Videotaped role play exercises in large sales management classes. Journal for Advancement of Marketing Education, 8, 32-37.

Mishra, R. K. (2015). Teaching-learning in a constructivist social science classroom. Journal of Educational Sciences \& Psychology, 5(2), 15-22.

Richardson, J. D., \& Kleiner, B. (1992). The relevant effectiveness of different training and development methodologies. Management Research Review News, 15(10), 23-26.

Tanner, J. F., \& Chonko, L. B. (1992). Avoiding the guillotine effect after video-taping role plays. Marketing Education Review, Spring, 37-41.

Taplin, R. (2007). Enhancing statistical education by using role-plays of consultations. Journal of the Royal Statistical Society: Series A (Statistics in Society), 170, 267-300. doi:10.1111/ j.1467-985X.2007.00463.x 